\title{
Formação de Professores em Foco: Uma Análise Curricular de um Curso de Licenciatura em Química
}

Thaís Andressa Lopes de Oliveira thais arievilo@hotmail.com Universidade Estadual de Maringá (UEM) Maringá, Paraná, Brasil

Fernanda lassenck de Matos Alves

fernandaiassenck@gmail.com Universidade Estadual de Maringá (UEM), Maringá, Paraná, Brasil

Mônica Patrícia de Almeida

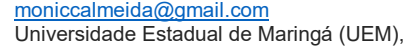
Maringá, Paraná, Brasil

Fernanda Alves Domingues dominguesf066@gmail.com Universidade Estadual de Maringá (UEM), Maringá, Paraná, Brasil

\section{André Luís Oliveira}

aloprof@gmail.com Maringá, Paraná, Brasil

\section{RESUMO}

O presente artigo é resultado de uma pesquisa documental que teve como objetivo analisar e discutir a proposta de formação inicial de professores de Química por meio da análise do Projeto Pedagógico do Curso (PPC) de um curso de licenciatura em Química de uma universidade pública federal. Para a constituição dos dados, foram analisadas a grade curricular do curso e as disciplinas que compõem o seu núcleo didático, tendo como aporte teórico autores que discorrem sobre formação de professores e a importância da análise dos currículos de cursos de licenciatura. Por meio das análises, observou-se que o curso atende às especificações legais quanto a carga horária mínima de disciplinas pedagógicas e, percebeu-se que a ementa das disciplinas está de acordo com os objetivos propostos para cada uma delas. Apesar de possuir disciplinas pedagógicas desde o 1 ํo período, o curso ainda tem sua estrutura voltada para a área específica. Prova disso, é que desde a criação do curso não foi oferecida nenhuma disciplina optativa da área de ensino. Constatamos, portanto, com essa pesquisa a necessidade de que os cursos de licenciatura, de um modo geral, tenham como sua base principal a formação de professores, de forma que os licenciandos possam participar ativamente do seu processo formativo.

PALAVRAS-CHAVE: Currículo. Formação Inicial de Professores. PPC. Licenciatura em Química. Ensino de Química. 


\section{INTRODUÇÃO}

Compreender e valorizar o significado da formação inicial do professor são pontos que devem ser levados em consideração quando se propõe pensar na melhoria da Educação Básica. A valorização do professor se inicia com o reconhecimento das políticas formativas que regem a profissão, bem como a realidade dos cursos de formação de professores.

Mesmo com a publicação da Lei de Diretrizes e Bases da Educação Nacional (LDB 9394/96), propondo alterações tanto para as instituições formadoras quanto para a formação de professores e, posteriormente, a publicação e aprovação de documentos específicos como Diretrizes Curriculares Nacionais para a Formação de Professores (BRASIL, 2002a) e as Diretrizes Curriculares para cada curso de licenciatura (BRASIL, 2002b) - essas aprovadas pelo Conselho Nacional de Educação -, os cursos de licenciatura nem sempre são reconhecidos.

A precariedade das condições de trabalho, a falta de incentivo e/ou interesse de jovens pela carreira do magistério, a ênfase em disciplinas de formação teórica (específicas da área) deixando em segundo plano as disciplinas de formação prática (cunho pedagógico), são alguns dos apontamentos que reforçam a necessidade de se debater sobre formação inicial de professores. Gatti $(2010$, p.3) comenta que:

[...] Mesmo com ajustes parciais em razão das novas diretrizes, verifica-se nas licenciaturas dos professores especialistas a prevalência da histórica ideia de oferecimento de formação com foco na área disciplinar específica, com pequeno espaço para a formação pedagógica [...].

Uma forma de refletir sobre a maneira como os cursos de licenciatura são tratados hoje pode ser realizada a partir da análise do Projeto Pedagógico do Curso (PPC), tendo em vista que o PPC além de contemplar a identidade do curso sobre os diversos aspectos (metodológico, teórico, organizacional), também oferece argumentos que embasam o transcorrer do processo de formação de professores, ou seja, no PPC podemos encontrar a descrição (com fundamentos teóricos e metodológicos) e as formas de organização do processo de formação, o que nos permite observar os objetivos, as diretrizes e a dinâmica de determinado curso.

Entendendo que, de acordo com a legislação os cursos de licenciatura têm como foco a formação de professores para a educação básica, é pertinente pensarmos e refletirmos sobre os currículos dos cursos de licenciatura, observando a proposta de formação na área específica, mas também, e principalmente, a formação pedagógica dos futuros professores. Neste contexto, o presente trabalho tem por objetivo analisar e discutir a proposta de formação inicial de professores de Química por meio da análise do PPC de um curso de licenciatura em Química de uma universidade pública federal.

\section{HISTÓRICO DAS POLÍTICAS DE FORMAÇÃO DE PROFESSORES}

As autoras Guedes e Ferreira (2002) realizaram um levantamento histórico da formação de professores, o qual é retratado no artigo História e Construção da Profissionalização nos Cursos de Licenciaturas. Este artigo foi usado como base para as reflexões históricas do período da década de 1930 até a década de 1970, apresentadas a seguir. 
As primeiras Faculdades de Filosofia Ciências e Letras, no Brasil, foram criadas na década de 1930, dando início aos primeiros cursos de formação de professores, em termos de licenciatura. Em 1931, ocorreu a reforma Francisco Campos, a qual estabeleceu critérios de organização do ensino secundário e as especificidades de formação dos professores que poderiam atuar nesta modalidade de ensino, sendo posteriormente promulgado pelo Governo provisório o Estatuto das Universidades Brasileiras por meio do Decreto 19.852 de 11/04/1931, ficando a cargo da Faculdade de Educação Ciências e Letras a responsabilidade pela qualificação de pessoas, as quais eram consideradas capazes de exercer o magistério, sendo que para este fim deveria ser utilizado um currículo seriado, o qual atendesse às exigências do momento. Essa Reforma Educacional de 1931, de acordo com Lopes (2007), foi a primeira a valorizar as Ciências. Destacamos neste aspecto a Química, que passou a ser obrigatória nos anos finais do ensino fundamental e nas séries complementares ao ingresso em cursos superiores.

Durante o Governo de Vargas, por meio da Lei № 7462 de 05/07/1937, a Universidade do Brasil se estruturou e, ao ser regulamentada pelo Decreto de Lei 1.190 de 04/04/1939 contava com uma sessão de pedagogia a qual era composta por um curso de duração de três anos e conferia ao aluno o título de Bacharel em Pedagogia. Tal sessão dispunha também do curso de Didática com duração de um ano e caso o bacharel o fizesse, o mesmo teria o título de licenciado. Sendo assim os cursos de Licenciaturas surgiram a partir do esquema " $3+1$ ".

No ano de 1961 foi aprovada a Lei 4.024, instituindo as Diretrizes e Bases da Educação Nacional. Seu Capítulo IV é voltado para o Processo de Formação do Magistério, tratando de assuntos como o ensino normal; a formação de professores para o grau médio nas Faculdades de Filosofia e cursos em Institutos de Educação. Um Artigo desta Lei de grande destaque foi o Artigo 49 que, após o Parecer 262/62 regulamentado pelo Conselho Federal de Educação, estabelecia, dentre outros aspectos, que os cursos de licenciatura em seus currículos mínimos deveriam conter as matérias fixadas do bacharelado, tendo a necessidade de se compreender e entender a licenciatura com um grau equivalente ao bacharelado e não igual a este.

Ainda na década de 60, as Universidades desenvolveram grandes discussões, com intuito de traçarem os direcionamentos a serem seguidos pela educação superior. Foi promulgada a Lei 5.540/68 referente à Reforma Universitária, o que acarretou algumas inovações trazidas para dentro da universidade como: a obrigatoriedade da frequência, a implantação do sistema de créditos, a manutenção dos cursos de pequena duração e a introdução de cursos de vestibular como único e classificatório.

No entanto, destaca-se no modelo de formação adotada pelas Universidades uma fragmentação entre as disciplinas específicas e as pedagógicas. Fato este visível até hoje e que, de acordo com Lôbo e Moradillo (2003) reflete na formação de um professor despreparado para lidar com a prática pedagógica.

Nas décadas citadas anteriormente, foram criados vários cursos de licenciatura. Contudo, por demandarem custos com manutenção, os cursos de Química não tiveram crescimento tão expressivo como as demais licenciaturas (MESQUITA; SOARES, 2011). Esses mesmos autores, realizaram um levantamento 
a Universidade Católica de Pernambuco, a Universidade Federal de Minas Gerais e a Universidade Federal da Bahia deram início a um curso de Química; no ano seguinte foi a vez da Universidade Federal do Rio Grande do Sul. Posteriormente, em 1950 a Universidade Federal do Sergipe seguiu os mesmos passos. Somente em 1958 a Universidade Federal do Ceará deu início ao curso de Química, e no ano de 1961 foi a vez tanto da Universidade Estadual Paulista Júlio de Mesquita Filho quanto da Universidade de Uberaba. Nos anos seguintes, em 1962 foi a vez da Fundação Universidade de Brasília, em 1963 a Universidade Federal do Amazonas e em 1964 FFCL de Ribeirão Preto - USP darem início ao curso de Química.

Posteriormente durante a década de 1970, foram implementados cursos de formação de professores que ficaram conhecidos como Esquema I para os profissionais de nível superior e, Esquema II, para os profissionais de nível médio. O profissional habilitado como professor poderia receber tal certificação a partir de uma complementação de 600 horas. Estes cursos de formação de professores criados em caráter emergencial para suprir as necessidades de profissionais para atuarem no ensino médio, tiveram grande crescimento, permanecendo os Esquemas (I e II) até a década de 1980 (MESQUITA; SOARES, 2011).

No ano de 1978 ocorreu o I Seminário de Educação Brasileira realizado na Universidade Estadual de Campinas. O Seminário deu início à reformulação dos cursos de formação de professores no Brasil cujo alicerce foram os cursos de Pedagogia e, posteriormente, as demais licenciaturas. Ressalta-se que os cursos de licenciaturas deveriam antes de tudo, formar o educador, sobressaindo-se assim a primazia do ato de educar sobre o ato de ensinar (DINIZ, 2012).

Discussões a respeito da reformulação dos cursos de formação de docentes foram ganhando destaque em 1980 quando a I Conferência Brasileira de Educação foi realizada na cidade de São Paulo. O intuito foi de articular as atividades dos docentes com as dos alunos, focando assim a reformulação dos cursos de licenciaturas no Brasil. As pesquisas desenvolvidas no âmbito do ensino de Química nesta época direcionavam as questões voltadas ao ensino e a aprendizagem dos conceitos químicos no Ensino Médio e também em questões formativas de licenciados em Química. As licenciaturas do curso de Química em sua grande parte ainda mantinham o funcionamento pelo esquema $3+1$ e buscavam a superação da visão tecnicista da educação na formação de professores. Conforme destaca Freitas (2002), esse período representou a ruptura com o pensamento tecnicista, tendo um avanço na concepção de formação do educador sendo que o mesmo deveria ter um amplo conhecimento de sua realidade com uma consciência crítica.

Outro avanço ocorrido na década de 80 e que contribuiu para a formação do professor foi a criação da Revista Química Nova na Escola, que acarretou o aumento das mobilizações de grupos de pesquisadores em ensino de Química na Sociedade Brasileira de Química, aumentando assim o número de encontros regionais e nacionais cujos focos das discussões eram pertinentes ao Ensino de Química (SCHNETZLER, 2002).

Quanto à formação docente na década de 1990, ela passou a ser especificamente exigida em nível superior, com a promulgação da LDB, Lei no 9.394/96 (MESQUITA; CARDOSO; SOARES, 2013). Conforme relata Diniz (2012, p. 15): 
[...] a década de 1990 passa a valorizar os saberes da experiência, a partir das discussões sobre os saberes que um educador e uma educadora precisam ter para se constituírem como profissionais da educação. Surge uma complexidade de teorias e práticas marcadas por rupturas com modelos ou pensamentos sobre o trabalho docente e formação de profissionais da educação estabelecidos anteriormente as quais são compatíveis com um sujeito que também produz saberes, sempre induzido pelas relações de poder fabricadas no ato de educar.

Com isso acentuou-se a exigência dentro das IES de que os cursos de licenciatura possuíssem um Projeto Político Pedagógico do Curso (PPPC ou PPC).

\section{FORMAÇÃO DE PROFESSORES E PROJETO POLÍTICO PEDAGÓGICO}

Atualmente pesquisas sobre formação de professores têm crescido consideravelmente. Alguns dos motivos para tal crescimento, segundo Zainko (2015) são: o desestímulo da juventude quanto à escolha do magistério; a ênfase na formação teórica em detrimento dos elementos práticos e; os modelos de formação inicial de professores destacando-se o currículo.

Autores como Gatti (2010), estudam a formação inicial de professores e consideram que, nos cursos de licenciatura ainda existe um maior enfoque para os conteúdos específicos, que claro, são importantes para um bom desempenho do professor ao lecionar o conteúdo de sua área. Porém, os cursos de licenciatura ainda destinam pouco tempo para a formação pedagógica.

Tal consideração pode ser vista no Projeto Pedagógico do Curso (PPC), definido por Libâneo (2004, p.151) como um

[...] documento que detalha objetivos, diretrizes e ações do processo educativo a ser desenvolvido na escola, expressando a síntese das exigências sociais e legais do sistema de ensino e os propósitos e expectativas da comunidade escolar [...]. O projeto, portanto, orienta a prática de produzir uma realidade: conhece-se a realidade presente, reflete-se sobre ela e traçam-se as coordenadas para a construção de uma nova realidade, propondo-se as formas mais adequadas de atender as necessidades sociais e individuais dos alunos.

No entanto o PPC de uma instituição de ensino é um documento por muitas vezes desconhecido pela comunidade escolar (ZAINKO, 2015), fato este que carece atenção, pois, como destaca Zanlorenzi e Pinheiro (2010), para um projeto pedagógico cumprir sua função verdadeira o mesmo deve constar de forma direta com a participação de toda a comunidade escolar em sua elaboração, pois assim será mais fácil a identificação de problemas vigentes do cenário escolar, bem como a identificação e estudo da comunidade atendida.

Tratamos de forma breve sobre o histórico das licenciaturas no Brasil, assim como da formação de professores no cenário brasileiro. A partir de agora, entramos nos tópicos que contemplam o trabalho, contextualização do curso, das disciplinas, as análises feitas pelas autoras e considerações finais acerca do trabalho. 


\section{O CURSO DE LICENCIATURA EM QUÍMICA ANALISADO}

O curso de Licenciatura em Química que nos propomos a analisar é relativamente novo. Sua aprovação se deu no ano de 2010 devido a exigência da abertura de um curso de licenciatura visto que a universidade em questão possui 05 cursos de Engenharia no referido campus. Seu reconhecimento pelo MEC se deu no final do ano de 2015, conquistando nota 4 na avaliação. Para manter a confidencialidade da IES que oferta o curso de licenciatura em Química analisado, denominaremos a IES, apenas, como Universidade $X$.

O curso é ministrado no período noturno, com duração de 08 semestres (04 anos) podendo ser concluído em até 12 semestres (06 anos). A regulamentação do curso é dada a partir das orientações contidas nas Diretrizes Curriculares Nacionais (DCN) dos cursos de Química, do Parecer do Conselho Nacional de Educação (CNE) da Câmara de Educação Superior (CES) (BRASIL, 2002c) e de documentos próprios da Instituição, como as Diretrizes Curriculares para os cursos de graduação.

De acordo com seu PPC, o objetivo do Curso de Licenciatura em Química é "formar o professor de Química para o Ensino Básico com ênfase no Ensino Médio, na perspectiva de uma atuação profissional eficiente, tendo o entendimento de que a ele cabe o papel de ser o agente de mudanças no contexto da educação" (PPC-X, 2010).

O curso formou até o presente momento 05 turmas de Licenciatura em Química. Embora novo, em 2013 o curso já passou por uma reformulação em sua grade curricular. Nesse contexto, é importante mencionar que a matriz curricular analisada neste artigo foi a versão reestruturada, na qual nos chamou a atenção, na ata de reformulação da matriz, a presença dos membros representantes do colegiado tanto docente quanto discente na discussão da alteração, o que tornou a reformulação mais próxima à realidade universitária, atendendo assim as necessidades elencadas por eles.

\section{METODOLOGIA}

A presente pesquisa é de natureza qualitativa, do tipo estudo de caso, e tem como principal aporte a análise documental que, segundo Lüdke e André (1986), consiste, a partir de questões e hipóteses de interesse, na busca de identificações factuais nos documentos. Para tanto, utilizamos como fonte de coleta o Projeto Pedagógico do Curso de Licenciatura em Química da Universidade X (PPC-X), além dos documentos que o regulamentam, como as DCN do curso de Química e o projeto de alteração de sua matriz curricular. Também tivemos relatos de uma licenciada egressa do curso, o qual chamaremos de AE. O olhar, as percepções e observações de AE foram importantes nas discussões uma vez que, possibilitou aos autores comparar os aspectos constantes na ementa das disciplinas com o que é realmente feito, isto é, contrastar a teoria dos documentos com a prática vivenciada durante a graduação.

Para a análise dos dados, tomamos como orientação as leituras de autores que tratam da formação de professores (PIMENTA; LIMA, 2004; ALARCÃO, 2005; GATTI, 2010; CONTRERAS, 2012) e de avaliação e análise curricular de cursos de licenciatura (GUEDES; FERREIRA, 2002; KASSEBOEHMER; CORRÊA; FERREIRA, 
2002; LIBÂNEO, 2004; LOPES, 2007; LIMA, ZANLORENZI; PINHEIRO, 2010; LIBÂNEO; OLIVEIRA; TOSCHI, 2012; ZAINKO, 2015).

Ao analisar o PPC do curso, buscamos considerar e refletir sobre questões como: o histórico do curso, sua organização, características do curso e das disciplinas, a fundamentação teórica que embasa o PPC, a participação dos docentes em sua reformulação, a forma como a educação e a profissão docente são tratadas, a estruturação do curso, perfil dos docentes, dos licenciados formados, a organização do currículo (se por disciplinas ou competências e habilidades), a matriz curricular, a estrutura física do curso, e as diretrizes de avaliação tanto do curso quanto das disciplinas, entre outras questões.

\section{RESULTADOS E DISCUSSÕES}

A primeira questão considerada foi a organização da Grade Curricular do curso. As disciplinas pedagógicas presentes no PPC de Licenciatura em Química foram analisadas, tendo como primeiro ponto a carga horária do curso e de suas disciplinas. Com a reformulação da matriz curricular ocorrida no ano de 2013, a grade passou de 3300 horas para 3155 horas. O departamento de Química da instituição justifica a redução de $145 \mathrm{~h}$ no curso por conta da necessidade de adequação e reestruturação das disciplinas de estágios vinculadas às disciplinas de Metodologia e Prática de Ensino de Química (MPEQ), a fim de possibilitar com isso "uma melhor relação entre o processo de ensino-aprendizagem. Além disso, como a carga horária mínima para o curso de Licenciatura é de 2800 h, exigido pela Resolução CNE/CP 2, de 19 de fevereiro DE 2002 (BRASIL, 2002b) neste caso o curso passou a ter 355h a mais do mínimo exigido" (PPC-X, 2010).

As disciplinas que compõem o corpus curricular estão distribuídas ao longo dos oito períodos do curso, sendo classificadas como pedagógicas e como atividade de síntese e integração do conhecimento. A soma das cargas horárias das disciplinas pedagógicas e de síntese e integração do conhecimento, incluindo as de Estágio Supervisionado 1, 2, 3 e 4, são de 990h/a, o que representa $28 \%$ da carga horária total de disciplinas do curso. Essa carga horária está de acordo com as normativas, que exigem que pelo menos um terço da carga horária disciplinar seja dedicada às disciplinas de conteúdos pedagógicos.

A seguir, apresentamos a análise de cada disciplina que compõe o segmento didático do curso de Licenciatura em Química analisado. Tal análise foi pautada no Projeto Pedagógico do Curso e de referenciais pertinentes a discussão de cada disciplina.

\section{ANÁLISE DAS DISCIPLINAS OBRIGATÓRIAS}

A matriz curricular do curso, sem considerar as disciplinas específicas, possui 17 disciplinas de formação pedagógica, são elas: 10 Período: Metodologia da Pesquisa em Educação; 20 Período: História da Educação, Libras 1 e Filosofia Geral; 3o Período: Psicologia da Educação e Libras 2; 4 Período: Didática e Políticas Educacionais; 5o Período: Organização e Gestão Escolar; Metodologia e Prática de Ensino de Química 1 e Estágio Supervisionado 1; 60 Período: Metodologia e Prática 
Prática de Ensino de Química 4 e Estágio Supervisionado 3; 8 Período: Metodologia e Prática de Ensino de Química 4 e Estágio Supervisionado 4.

Tendo em vista que são sequenciais, e também por questão de organização, optamos por descrever as análises agrupando as disciplinas de Libras (1 e 2), Metodologia e Prática de Ensino em Química (1, 2, 3 e 4) e Estágio Supervisionado $(1,2,3$ e 4$)$.

Para conhecimento e facilitação da leitura, as siglas constantes nas análises a seguir referem-se à: AT: Atividades Teóricas; AP: Atividades Práticas; TA: Total de Aulas presenciais; APCC: Aulas Práticas como Componente Curricular; APS: Atividades Práticas Supervisionadas.

\section{Metodologia da Pesquisa em Educação}

Com 36h/a de carga horária, a disciplina Metodologia da Pesquisa em Educação (METEPE) é a única disciplina pedagógica trabalhada no 10 período do curso. Sua carga horária é distribuída em 24h/a de Atividades Teóricas (AT), 10h/a de Atividade Prática como Componente Curricular (APCC) e 2h/a de Atividade Prática Supervisionada (APS).

Em sua ementa, busca-se introduzir aos licenciandos os fundamentos básicos para a produção e análise de pesquisas em educação, de acordo com os seguintes objetivos:

\footnotetext{
Apresentar ao aluno os conceitos de ciência e produção do conhecimento científico. Compreender as diversas fases de elaboração e desenvolvimento de pesquisas e trabalhos acadêmicos. Capacitar o aluno para a produção de projetos de pesquisa em educação e trabalhos científicos obedecendo as normas da ABNT [e da instituição] (Universidade X, 2013).
}

Segundo Schnetzler (2004), o domínio do conhecimento químico não é suficiente para o desenvolvimento de pesquisas em ensino frente a complexibilidade de seu objeto de estudo. Formar o futuro professor para a realização de pesquisas pode viabilizar a construção de um olhar mais crítico sobre a prática docente, visto que o professor que reconhece a necessidade de pesquisar sobre seu ensino, ou de buscar melhorá-lo com base em pesquisas feitas por outros pesquisadores, tem um olhar mais acurado sobre os motivos que causam problemas na aprendizagem de seus alunos.

Nessa perspectiva, dentre os procedimentos de ensino propostos na disciplina está a "reflexão e debate sobre a evolução e as pesquisas científicas realizadas na área de Química e sua transposição didática para o conteúdo do ensino médio" (Res. no 059/2013 - COEPP). Assim, ao compreender a pesquisa como uma busca por respostas a questões a que se propõe investigar, os acadêmicos compreendem também a sala de aula como um objeto de estudo em potencial.

\section{História da Educação}

A disciplina História da Educação é ministrada no 2ำ período, e possui carga horária total de 36h/a, distribuídas em $34 \mathrm{~h} / \mathrm{a}$ de AT, e $2 \mathrm{~h} / \mathrm{a}$ de APS. Sua ementa alicerça-se na promoção de discussões a respeito das principais tendências dos 
pensamentos filosóficos e pedagógicos, de forma a possibilitar a compreensão e reflexão do processo histórico, bem como a importância de se estudar essa disciplina para a compreensão da educação atual brasileira.

Tais objetivos estão acordados com Contreras (2012) ao afirmar que à medida que se conhece a história da formação de professores, o professor começa a se reconhecer como profissional com direitos, deveres, e desafios inerentes à profissão.

\section{Libras 1 e Libras 2}

A disciplina de Libras 1 é ministrada no 20 período e a de Libras 2 no 3응 período. Ambas possuem carga horária total de $36 \mathrm{~h} / \mathrm{a}$, distribuídas em 24h/a de AT; $10 \mathrm{~h} / \mathrm{a}$ de APCC e; $2 \mathrm{~h} / \mathrm{a}$ de APS. Para Libras 1 não há pré-requisitos enquanto que, para cursar Libras 2 é necessário ter feito a Libras 1.

De acordo com o PPC, a disciplina de Libras 1 visa apresentação da língua ao licenciando, a fim de possibilitar a ele um conhecimento básico para uma futura aproximação da realidade escolar de um aluno com deficiência auditiva. Já a disciplina de Libras 2 visa a apresentação de conceitos, concepções, variações e diversas formas de exploração do uso da Libras.

A disciplina de Libras, de um modo geral, tem como foco a inclusão, sendo que a Constituição Federal de 1988 em seu artigo 205 (BRASIL, 1988) garante a todos o direito a educação. No entanto, ao analisarmos a real condição da presença dos alunos surdos em sala de aula percebemos que os mesmos são ainda prejudicados, pois, geralmente, seus intérpretes não possuem formação nas disciplinas que "traduzem" aos seus alunos com deficiência auditiva. De acordo com Lodi (2013), a aprendizagem dos alunos surdos acaba sendo de responsabilidade do intérprete, como pode ser observado na fala a seguir:

[...] a construção dos conhecimentos escolares pelos alunos no período regular de escolarização ganham menor importância, já que os processos envolvendo a Libras (língua que possibilitaria a participação e a aprendizagem dos alunos surdos) acabam sendo de responsabilidade dos tradutores e intérpretes (com papel e formação não definidos) [...] (LODI, 2013, p.56).

Nesse contexto, a inclusão das disciplinas de Libras no PPC dos cursos de licenciatura é de suma importância para a formação dos futuros professores, sendo a base inicial para a discussão e reflexão sobre aspectos inclusivos. Desse modo, da análise realizada, pode-se inferir que os objetivos apresentados nas disciplinas de Libras 1 e 2 estão acordadas às ementas, e possibilitam aos licenciandos ter um conhecimento teórico e prático da Libras.

\section{Filosofia Geral}

A disciplina de Filosofia Geral apresenta carga horária total de 36 h/a, distribuídas em $A T=34 h / a$ e APS= 2h/a. Não há pré-requisitos nesta disciplina, nem equivalência.

A disciplina de Filosofia Geral visa apresentar origens e críticas acerca da finalidade social da educação. Nessa perspectiva, os objetivos da disciplina estão 
relacionados à formação do espírito crítico dos estudantes para as diversas realidades da sociedade, suas pluralidades e desafios; promover a capacidade argumentativa e; fomentar debates em torno de temas próprios da Filosofia, com ênfase ao exercício da profissão, da cidadania plena e da responsabilidade social (Res. 059/2013-COGEP, 2013).

Consideramos muito relevante a presença de uma disciplina de Filosofia na grade do curso de Química, visto que é uma área do conhecimento essencial para a compreensão da evolução do pensamento científico ao longo dos séculos. Como Greenberg (2010) recorda, a Química como ciência não surgiu de uma hora para outra, e por esse motivo compreender que ela foi resultado de um amadurecimento filosófico e intelectual da sociedade é essencial para localizarmos onde a ciência se encontra na sociedade nos dias atuais.

\title{
Psicologia da Educação
}

Ministrada no 3ํ período do curso, a disciplina Psicologia da Educação possui carga horária total de $54 \mathrm{~h} / \mathrm{a}$, distribuídas em 41h/a de AT; 10h/a de APCC e; 3h/a de APS. Segundo o documento, as APCC devem ser conduzidas de forma contínua ao longo da execução da disciplina, sendo intercaladas aos conteúdos trabalhados nas AT. Como pré-requisito, o acadêmico deve já ter cursado a disciplina História da Educação.

Visto que a psicologia deve proporcionar ao licenciando estudar o comportamento humano e as condições necessárias para a vida em sociedade (KASSENBOEHMER; CÔRREA; FERREIRA, 2010), a ementa inclui como parte de seus conteúdos programáticos o estudo das "principais teorias da psicologia aplicadas a educação escolar. Processos psicológicos da aprendizagem e abordagens cognitivas. Reflexão sobre temas contemporâneos do campo da Educação" (Res. 059/2013-COGEP), além das implicações psicológicas, sociais e políticas; e o estudo da deficiência e dificuldade de aprendizagem - a educação inclusiva.

Quanto aos objetivos da disciplina estão:

\begin{abstract}
[...] Possibilitar que os estudantes se apropriem de princípios teóricos básicos dessa área do conhecimento, a fim de que desenvolvam a capacidade de análise das diferenças e divergências entre as correntes da Psicologia da Educação e de compreensão dos princípios e pressupostos que fundamentam os modelos de desenvolvimento e de ensino-aprendizagem delas decorrentes. Promover a reflexão sobre temas contemporâneos do campo da Educação à luz das teorias da psicologia estudadas (Res. 059/2013-COGEP).
\end{abstract}

Tais objetivos estão a nosso ver acordadas a ementa proposta, à medida que possibilitam ao futuro professor conhecer melhor seus alunos, a forma como se relacionam e se desenvolvem no meio social.

\section{Didática Geral}

Ministrada no 4ำ período do curso, a disciplina de Didática Geral possui carga horária total de $36 \mathrm{~h} / \mathrm{a}$, distribuídas em 24h/a de AT; 10h/a de APCC e 2h/a de APS. Como pré-requisito é necessário ter cursado a disciplina de Psicologia da Educação. 
A disciplina de Didática Geral visa apresentação de conceitos, concepções, elaboração e elementos do planejamento educacional, a prática de avaliação, organização do trabalho em sala e a relação professor aluno. Dessa forma, entre seus objetivos estão:

Promover a discussão crítica sobre os princípios e os pressupostos históricos, filosóficos, políticos e sociais que fundamentam a ação docente nas diferentes abordagens do processo de ensino-aprendizagem, tendo em vista as concepções de sociedade, homem, educação, ensino-aprendizagem, metodologia, avaliação e a relação professor-aluno que permeiam esse processo. Possibilitar a reflexão crítica sobre o planejamento escolar enquanto elemento norteador do processo de ensino-aprendizagem, articulando seus elementos básicos às concepções de educação e conhecimento que fundamentam a prática docente (Res. 059/2013-COGEP).

De acordo com Pimenta e Lima (2004), o contato do aluno-professor com os fundamentos da sala de aula possibilita a construção de sua identidade docente, no que diz respeito ao planejamento escolar e a reflexão sobre a prática. Para tal, o plano de ensino da disciplina apresenta sua carga horária subdividida em AT, APS e APCC, nas quais os discentes são avaliados por meio da produção de planos de aula e regência. Segundo o projeto de alteração curricular, a disciplina de Didática é de importância considerável para a formação do licenciando, visto que é por meio dela que o aluno de licenciatura em Química tem o primeiro contato com as diferentes tendências de ensino, a organização escolar, e começa a construir sua concepção de escola e de ensino.

\section{Políticas Educacionais}

Assim como em Psicologia da Educação, a disciplina Políticas Educacionais possui como pré-requisito História da Educação, tendo carga horária total de $36 \mathrm{~h} / \mathrm{a}$, distribuídas em $34 \mathrm{~h} / \mathrm{a}$ de AT e $2 \mathrm{~h} / \mathrm{a}$ de APS. A disciplina é ministrada no 4 o período do curso e inclui em sua ementa o estudo das políticas educacionais, da legislação e suas implicações para a organização da atividade escolar, da organização da educação brasileira: dimensões históricas, políticas, sociais, econômicas e educacionais; e a análise das relações entre educação, estado e sociedade.

Tais conteúdos estão em concordância com os objetivos apresentados para a disciplina, que entre outros pontos contempla: "Promover a reflexão crítica sobre o sistema escolar e o trabalho do professor no contexto das reformas do estado e das transformações da sociedade contemporânea" (Res. 59/2013-COEPP), à medida que conhecer e compreender as leis que regem o trabalho docente é essencial à prática do licenciando.

O professor, enquanto profissional, deve conhecer as leis que orientam sua prática, bem como os direitos e deveres que the são implicados (LIBÂNEO; OLIVEIRA; TOSCHI, 2011; CONTRERAS, 2012). Diante do exposto, assim como é relevante o estudo da História da Educação, consideramos também importante o estudo das políticas formativas que regulamentam a profissão professor. Concordamos com Contreras (2012) quanto à necessidade do licenciando se reconhecer como profissional, dotado de direitos e deveres na sociedade, 
resultado de um conjunto de políticas organizacionais dentro do contexto histórico de uma sociedade.

\section{Organização e Gestão Escolar}

Situada no 5o período do curso, a disciplina Organização e Gestão Escolar possui como pré-requisito Políticas Educacionais. Sua carga horária total é de 36h/a, distribuídas em 30h/a de AT, 4h/a de APCC e 2h/a de APS. Tal disciplina possui como objetivo geral a promoção de discussões críticas de concepções as quais fundamentam as teorias que regem a organização e gestão escolar e do trabalho administrativo pedagógico; e como objetivos específicos:

[...] Promover a compreensão crítica sobre os conceitos de gestão
participativa e cultura organizacional, articulando os ao princípio de trabalho
coletivo e colaborativo para o desenvolvimento do processo educativo.
Possibilitar o estudo sobre o Projeto Político-Pedagógico, enquanto plano
global das instituições escolares, a partir do princípio de democratização da
escola pública. Promover a reflexão crítica sobre a atuação participativa e o
papel dos educadores e da comunidade escolar nas práticas de organização e
gestão da escola, bem como na transformação dessas práticas.

A disciplina de Organização e Gestão Escolar tem como um dos focos de ensino e estudo o Projeto Político Pedagógico (PPP) das escolas. De acordo com Libâneo (2004), é necessário que o PPP de qualquer que seja a instituição de ensino tenha como o foco central a qualidade cognitiva das aprendizagens. Ainda segundo o autor, a escola:

[...] provê formação cultural e científica, que possibilita o contato dos alunos com a cultura, aquela cultura provida pela ciência, pela técnica, pela linguagem, pela estética, pela ética. Especialmente, uma escola de qualidade é aquela que inclui, uma escola contra a exclusão econômica, política, cultural, pedagógica (LIBÂNEO, 2004).

Tais aspectos escolares, conforme o citado pelo autor, devem ser relatados no PPC, sendo os mesmos discutidos na disciplina de Organização e Gestão Escolar, ressaltando a importância da mesma para a formação de um professor crítico. Outro aspecto importante a ser ressaltado é que essa disciplina anteriormente era ofertada no sexto período do curso, e foi alterada para o quinto período do curso; outra alteração realizada foi com relação a disciplina de pré-requisito, que anteriormente era a disciplina de Metodologias do Ensino de Química e, que agora com a alteração passou a ser a disciplina de Políticas Educacionais. De acordo com o PPC as alterações foram necessárias, pois os conteúdos abordados na disciplina de Organização e Gestão Escolar são iniciados na disciplina de Políticas Educacionais.

\section{Metodologia e Prática de Ensino de Química (MPEQ) 1, 2, 3 e 4}

A disciplina de Metodologia e Prática de Ensino (MPEQ) é subdividida em 4 disciplinas ministradas ao longo dos quatro últimos semestres, nomeadas MPEQ 1, MPEQ 2, MPEQ 3 e MPEQ 4. Cada disciplina de MPEQ tem como carga horária total 36 horas/aula, distribuídas em: 11h/a de AT; 02h/a de APS e 23h/a de APCC. 
Sobre os pré-requisitos, para cursar a disciplina de MPEQ 1 (5 período) o licenciando deve ter concluído as disciplinas de Didática e Políticas Educacionais (ambas do 4ㅇ período). A partir da disciplina MPEQ 2 (6 período), cada MPEQ é co-requisito da outra, junto a cada estágio correspondente.

Quanto a ementa das disciplinas, tem-se os seguintes conteúdos estruturantes:

MPEQ 1: A relação entre escola e comunidade escolar (Observação e investigação da realidade e do contexto escolar/Metodologia e técnicas de observação e entrevista). Identidade profissional docente, saberes profissionais docentes e professor reflexivo. Ciência e Educação para a Química - CTSA (Ciência, Tecnologia, Sociedade e Ambiente). A Ciência e o dia a dia Escolar;

MPEQ 2: Visão geral sobre a origem, evolução, importância e campo atual de estudo da área de Ensino de Química. Análise crítica de currículos e programas de Química na Educação Básica. Planejamento, objetivos, conteúdos, métodos de ensino, Avaliação;

MPEQ 3: Analogias no ensino de Química; Atividades teórico-experimentais para o ensino de Química na educação básica; Vivência da prática docente e observação de contextos de ensino de Química; Seleção de conteúdos para o ensino de Química; Planos de aula e planejamento de regências;

MPEQ 4: Organização, planejamento e execução de atividades de ensino de Química na educação básica, A pesquisa em ensino de Química e suas contribuições para a prática docente, Elaboração e desenvolvimento de projeto de pesquisa, As contribuições e os limites das TIC no processo de ensino-aprendizagem de Química.

Observa-se que as ementas das disciplinas de MPEQ seguem uma ordem sequencial que possibilita ao licenciando construir gradativamente competências e habilidades necessárias a atuação docente. Tais especificidades estão de acordo com alguns dos objetivos das disciplinas como "Compreender as especificidades da Química como Ciência e Disciplina Escolar" e "Proporcionar uma visão geral sobre a origem, evolução, importância e campo atual de estudo na área de Ensino de Química".

Ademais, as disciplinas de MPEQ apresentam no PPC aspectos formativos que devem ser trabalhados durante o desenvolvimento da disciplina, os quais destacamos a reflexão sobre a prática e a abordagem CTSA, que é citada durante todo o documento, sendo a mesma um dos focos formativos do futuro professor.

A importância de se trabalhar na perspectiva CTSA na formação inicial é citada por Santos e Schnetzler (2000), que afirmam que um ensino de química, para formação de um cidadão crítico, deve estar centrado na inter-relação de dois componentes básicos: a informação química e o contexto social, pois para que o aluno possua um papel ativo na sociedade, ele não precisa simplesmente conhecer a química, mas como a química está inserida na sociedade. E para que este objetivo seja alcançado a formação inicial do futuro professor pode ter um papel crucial para que durante seu exercício profissional ele possa formar um aluno/cidadão crítico.

Para que o professor compreenda a importância de formar um aluno crítico, que reflete sobre o meio em que vive, é necessário que ele compreenda primeiro a importância de ser um profissional que reflete sobre sua prática (ALARCÃO, 
2005). Ao descrever um professor reflexivo, Alarcão (2005) relata que este é como um profissional que necessita saber quem é e as razões pelas quais atua; e é um profissional que sempre está conscientizando-se do lugar que ocupa na sociedade. De acordo com a autora "os professores têm de ser agentes ativos do seu próprio desenvolvimento e do funcionamento das escolas como organização ao serviço do grande projeto social que é a formação dos educandos" (ALARCÃO, 2005, p. 177).

Dessa forma, com base nas sucintas reflexões apresentadas acima, pode-se compreender a importância da disciplina de MEPQ, na formação inicial de futuros professores.

\section{Estágio Supervisionado 1, 2, 3 e 4}

Assim como a disciplina de MPEQ, o Estágio Supervisionado também é subdividido em 4 disciplinas ministradas ao longo dos quatro últimos semestres do curso, sendo elas: Estágio Supervisionado 1, Estágio Supervisionado 2, Estágio Supervisionado 3 e Estágio Supervisionado 4. Sua organização, de acordo com o PPC do curso, deve estar "em consonância com disciplinas de caráter pedagógico, histórico-filosófico e metodológico concomitantes às unidades disciplinares correspondentes de estágio ao longo dos semestres". A carga horária das disciplinas varia de acordo com o período em que são ofertadas, sendo distribuída conforme Quadro 01, a seguir.

Quadro 01 - Distribuição da Carga Horária das disciplinas Estágio 1, 2,3 e 4 (em h/a).

\begin{tabular}{c|c|c|c|c}
\hline Carga Horária & Estágio 1 & Estágio 2 & Estágio 3 & Estágio 4 \\
\hline APS & 5 & 5 & 8 & 10 \\
\hline TA & 85 & 85 & 136 & 170 \\
\hline Carga horária total & 90 & 90 & 144 & 180 \\
\hline
\end{tabular}

Fonte: Autoria Própria (2017).

Sobre a alteração na grade curricular com relação aos Estágios, o PPC descreve que:

\footnotetext{
Para assegurar uma profunda e intensa relação entre teoria e prática, sugerimos que as vivências da prática profissional, inscritas nos momentos de estágio supervisionado, sejam subsidiadas e orientadas pela teoria e que, a partir da prática, se reflita criticamente sobre o papel da teoria na qualificação do fazer docente [...] (Res. no 059/2013-COGEP, p. 08).
}

A importância de se ter a prática integrada à teoria faz-se presente na justificativa para incorporação de fato do Estágio Supervisionado na grade curricular, sendo que cada uma das disciplinas de Estágio Supervisionado é prérequisito para cursar a próxima.

Quanto aos objetivos das disciplinas, observamos que estes estão em concordância com a ementa apresentada, levando em conta os aspectos formativos aprendidos nas disciplinas de MPEQ.

Desse modo para o Estágio Supervisionado (ES) tem-se os seguintes objetivos: 
ES 1: Oferecer ao discente a oportunidade de experimentar situações de efetivo exercício profissional como professor de Química em escolas do ensino médio, por meio de observações e análises dos entornos escolares, entrevistas, participações e análise de projetos políticos pedagógicos e semanas pedagógicas dos ambientes estudados.

ES 2: Realizar a análise crítica dos materiais e recursos didáticos disponíveis e utilizados na participação, observação e análise dos Horários de Trabalho do Professor (HTP); acompanhamento do planejamento de ensino e de aula [...].

ES 3: Oferecer ao discente a oportunidade de experimentar situações de efetivo exercício profissional [...]. Planejamento, desenvolvimento e avaliação de regências para o ensino de Química no ensino médio, contemplando atividades teóricas e experimentais com prática laboratorial. Montagem de equipamentos de laboratório. Oferecer oportunidade para que o licenciando desenvolva atitude crítica quanto ao trabalho educativo.

ES 4: Observação e análise do trabalho do professor de Química do ensino médio, Planejamento, desenvolvimento e avaliação de regências teóricoexperimentais, Elaboração e desenvolvimento de um projeto de pesquisa em ensino de Química a ser desenvolvido na escola-campo de estágio, Regências, A utilização das TIC no processo de ensino aprendizagem de Química, Orientação e embasamento teórico, Elaboração de Relatório.

Para Krasilchik (2004) o estágio é o momento mais importante da formação do futuro professor. Segundo ela, é nesse momento que o licenciando se insere efetivamente em sala de aula, passando a se enxergar como professor, dotado de obrigações e responsabilidades. Além disso, para o professor que recebe o aluno de licenciatura em sua sala o estágio é um momento de formação continuada, à medida que são estabelecidas relações entre escola e universidade, e entre professor-monitor e professor de prática de ensino (KRASILCHIK, 2004). Para Pimenta e Lima (2004), o estágio é uma oportunidade de formação tanto para quem não exerce o magistério, quanto para quem já o exerce numa proposta de formação em que todos refletem sobre a prática docente.

Um ponto relevante de se mencionar quanto a carga horária das disciplinas de estágio supervisionado do curso em análise é como esta aumenta conforme se avança nos períodos do curso. Segundo Krasilchik (2004) o tempo de estágio deve ser incluído no horário dos alunos. Diante disso acreditamos que esse aumento gradual da carga horária de estágio reflete num amadurecimento do aluno de licenciatura: inicialmente estando presente em sala como um imitador de modelos, buscando separar teoria e prática a medida que aproxima a realidade das tendências de ensino aprendidas no curso de formação, até ser capaz de refletir sobre sua prática, construindo sua identidade docente (PIMENTA; LIMA, 2004).

Como Krasilchik (2004, p.168) destaca “os estágios só poderão servir plenamente a seus fins, se os estagiários passarem a sentir-se elementos da escola, e não estranhos a ela". Por esse motivo, o diálogo entre todas as partes envolvidas na inserção do estagiário na escola é essencial para a criação de um espaço de cooperação e aprendizado mútuo.

Sobre a avaliação do Estágio Supervisionado, o PPC do curso destaca a proposta de se fazer uma "Mostra de Estágio", afim de socializar os trabalhos e estudos desenvolvidos ao longo das 4 disciplinas, podendo ter abrangência local ou regional. 


\section{Disciplinas Optativas}

Além das disciplinas de caráter obrigatório, descritas na seção anterior, a grade curricular do curso analisado compreende entre o 70 e 8o período 144hs/aula de disciplinas optativas, que devem ser escolhidas por área de conhecimento. O aluno deverá, portanto, cursar tal carga horária dentre as 21 disciplinas listadas no ementário. Desse número, 11 pertencem ao segmento pedagógico, possuindo 36hs/a cada. São elas: Recursos Audiovisuais aplicados ao ensino; Tecnologias da Informação e Comunicação aplicadas ao Ensino de Química; Educação, Trabalho e Sociedade; Organização da Escola Básica; Educação de Jovens e Adultos; Ensino Médio: Organização Curricular, Planejamento e Avaliação; Teoria do Currículo; Intervenção Pedagógica e Necessidades Educacionais Especiais; Desenvolvimento Humano e Aprendizagem; Pluralidade Cultural e Orientação Sexual; História e Cultura Afro-Brasileira.

No presente trabalho, consideramos relevante mencionar a existência das disciplinas optativas de cunho pedagógico nos documentos orientadores, porém optamos por não discutir tais disciplinas, pois apesar de constarem no Projeto Curricular do Curso, segundo AE, elas nunca foram ofertadas no curso.

\section{CONSIDERAÇÕES FINAIS}

Realizar a análise do currículo de um curso de licenciatura não é tarefa fácil. Diante do emaranhado de Diretrizes, Leis, Regulamentos, Resoluções, deve se estar atento a melhor forma de articular tais documentos com a fundamentação teórica e os objetivos contidos no Projeto Político do Curso, PPC.

O curso analisado é relativamente novo, todavia já passou por uma reformulação em sua grade curricular no ano de 2013. Seu PPC não especifica claramente a trajetória do curso mas contempla as adequações legais para criação do mesmo. Pensamos que seja importante ter todas as informações pertinentes ao curso descritas no PPC, pois tais informações ajudam a contar a trajetória do curso, quais os objetivos, intenções, adequações legais, valores, entre outros. As propostas contidas em seu PPC, Planos de Ensino e Ementas são interessantes, pois pensam no professor e na sua prática, contudo, por se tratar de um curso de licenciatura, sentimos que ainda é preciso um olhar mais aprofundado para a profissão professor. Inclusive julgamos que seria importante apresentar o PPC aos licenciandos no decorrer de alguma das disciplinas de formação pedagógica, afinal tal ação deveria fazer parte da formação do futuro professor.

Sobre a formação do licenciando, embora tenhamos sentido que o curso possui um foco voltado mais para o bacharelado, entendemos que a discussão sobre a articulação que deve ser feita entre teoria e prática, instiga o licenciando a exercer a prática reflexiva, o qual é considerada relevante não apenas no curso, mas também na sociedade na qual está inserido.

Com relação à caracterização do curso, não identificamos a descrição da estrutura física da Instituição para desenvolver o curso nem a avaliação do curso no âmbito do Sistema Nacional de Avaliação do Ensino Superior. A informação que tivemos sobre tal questão foi através de conversa com $A E$, a qual destacou que o 
professores mestres e doutores. Outro ponto que consideramos pertinente é a carga horária total do curso que se encontra em conformidade com as DCN para os cursos de licenciatura, uma vez que o mínimo exigido é de 2800 horas e, o curso apresenta 3155 horas.

As disciplinas específicas da área são tratadas como conteúdos básicos. Ora considerando o conceito de básico, que remete à fundamental, essencial, então as disciplinas pedagógicas deveriam ser pensadas como sendo conteúdos básicos também. Tudo bem que nos atentamos a uma mera palavra, mas pensando que o professor deve ser sensato inclusive com suas palavras, tal observação feita pelos autores não é em vão. Além disso, tal citação nos leva a pensar no curso voltado para o bacharelado e não para licenciatura.

Sobre as disciplinas componentes do 10 período, observamos que houve a solicitação para que a disciplina de Metodologia de Pesquisa fosse tida como Metodologia de Pesquisa em Educação, isto porque a segunda aborda a pesquisa científica especificamente em educação, sendo este foco, portanto mais adequado para a formação do profissional licenciado em Química. Concordamos que o projeto que deve ser desenvolvido pelos alunos da disciplina deva ser sim na área da educação. Todavia, questionamos o embasamento teórico que tais alunos têm para elaborar tal projeto, uma vez que a disciplina é a única de vínculo pedagógico inserida no 10 período. Que embasamento teórico para fazer reflexão um licenciando que acabou de ingressar no curso, tendo somente uma disciplina de formação pedagógica no 10 período pode ter? Além do mais, metodologia remete ao método, à técnica e à proposta da disciplina é observar o método das pesquisas em educação ou os estudos em pesquisa em educação? Pensamos que talvez metodologia não fosse a palavra ideal para nomear a disciplina ou, o seu foco deve ser alterado.

Observamos também que há a disciplina de História da Educação no 2o período, mas não há na matriz curricular, tampouco nas ementas das disciplinas pedagógicas, conteúdo referente à evolução e desenvolvimento da Química. Como pesquisadores da pós-graduação e eternos aprendentes da História e Epistemologia da Ciência, hoje compreendemos o quão importante se faz saber sobre a História da Ciência e/ou Química, e a relevância de que suas discussões sejam incorporadas desde a graduação.

Sobre os Estágios Supervisionados consideramos interessante a proposta de fragmentá-los em 04 períodos, assim como acontece com as disciplinas de MPEQ que são co-requisitos para os Estágios. Pensamos ser bem articulado à ideia de discutir conteúdos em MPEQ e desenvolvê-los e pensá-los nas práticas de Estágio. Porém, pensamos que tais disciplinas poderiam ser iniciadas antes e não apenas no 5o período. No Projeto de reformulação do Curso consta que

[...] a inserção do licenciando em um contexto de atuação profissional tornase indispensável, uma vez que permite seu contato com o cotidiano escolar e com a prática profissional docente. [...] Parte-se do pressuposto de que um processo formativo deve proporcionar um espaço que contemple a complexidade do trabalho docente, privilegiando a prática atrelada à teoria. Tal espaço configura-se curricularmente nos Estágios Supervisionados, cuja estrutura tem sido foco de intensas discussões teórico metodológicas [...] (P. №. 032/13-COGEP -, 2013 p.7-8). 
Mas na prática tal inserção acontece passado metade da graduação. Por mais que o aluno ainda não tenha embasamento teórico para adentrar uma escola, a relação teoria e prática deve ser vista e vivida durante toda a graduação do licenciando.

Sobre as disciplinas optativas sentimos mais uma vez que a intenção foi focar no curso de bacharelado e não de licenciatura. Chamou-nos atenção que a disciplina de pluralidade cultural e orientação sexual foi retirada do núcleo de disciplinas complementares para compor o núcleo de optativas. A justificativa para a retirada, de acordo com o PPC deve-se ao fato da disciplina não contemplar o núcleo de conteúdos básicos e ainda, mesmo que se reduza 30 horas na matriz curricular esta ainda possuirá 3155 horas, 355 horas a mais do que mínimo exigido. Francamente não pensamos que o fato de ter "carga horária sobrando" seja justificativa para solicitar a retirada de uma disciplina.

Aliás, lendo o PCC observamos que há 20 disciplinas optativas, sendo 10 focadas em conteúdo de formação específica em Química e 10 com foco em conteúdo de formação pedagógica. De certa forma a proporção é até justa, não fosse o fato de sabermos em conversa com AE que, para as 04 turmas até então formadas só foram ofertadas as optativas na área "dura". Pensando que o curso é de licenciatura, entendemos que tal observação seja pertinente e carente de atenção.

Percebemos que, embora os objetivos e ementas das disciplinas de formação pedagógica em geral sejam fundamentados teoricamente e revelem preocupação com a formação de professores de maneira a articular teoria e prática, o PPC assim como o Projeto de Reformulação da Grade Curricular e também a Matriz do curso carecem olhar para o principal foco que um curso de licenciatura deve ter: formar professores. Dotados de conhecimento específico da área de Química sim, mas também, e tão importante quanto, possuidores de embasamento pedagógico que permita a reflexão sobre sua prática, a fim de que tal reflexão possa interferir na ação que o professor mais tem poder: a de ensinar. 


\title{
Teacher Training in Focus: An Analysis of a Curriculum Degree in Chemistry
}

\begin{abstract}
The present article is the result of a documentary research that had as objective to analyze and to discuss the proposal of initial formation of professors of Chemistry by means of the Analysis of the Pedagogical Project of the Course (PPC) of a course of degree in Chemistry of a federal public university. In order to compose the data, the curricular curriculum of the course and the disciplines that compose its didactic nucleus were analyzed, with the theoretical contribution of authors that talk about teacher education and the importance of the curriculum analysis of undergraduate courses. Through the analysis, it was observed that the course complies with the legal specifications regarding the minimum hours of pedagogical subjects and it was noticed that the subjects' syllabus is in accordance with the proposed objectives for each of them. Despite having pedagogical disciplines since the first period, the course still has its structure focused on the specific area. Proof of this is that since the creation of the course no optional discipline of the teaching area has been offered. Therefore, we have identified the need for undergraduate courses in general to be based on teacher training, so that graduates can actively participate in their training process.

KEYWORDS: Curriculum. Initial Teacher Training. PPC. Chemistry graduation. Chemistry teaching.
\end{abstract}




\section{REFERÊNCIAS}

ALARCÃO, I. Formação reflexiva de professores: estratégias de supervisão. Porto: Porto Editora, 2005.

BRASIL. Senado Federal. Constituição da República Federativa do Brasil. Brasília 1988.

BRASIL. Ministério da Educação e Cultura. Lei 9.394, de 20 de dezembro de 1996. Estabelece as diretrizes e bases da educação nacional. Diário Oficial da União, Poder Legislativo, sec. I, n. 248, p. 27.833, Brasília, 23 dez. 1996.

BRASIL. Ministério da Educação. Conselho Nacional de Educação Conselho Pleno. Resolução $n^{\circ}$ 1, de 18 de fevereiro de 2002a. Disponível em: < http://portal.mec.gov.br/cne/arquivos/pdf/rcp01_02.pdf>. Acesso em: 25 mar. 2017.

BRASIL. Ministério da Educação. Conselho Nacional de Educação Conselho Pleno. Resolução ${ }^{\circ}$ 2, de 19 de fevereiro de 2002b. Disponível em: < http://portal.mec.gov.br/cne/arquivos/pdf/CP022002.pdf>. Acesso em: 22 mar. 2017.

BRASIL. Ministério da Educação. Conselho Nacional de Educação Câmara de Educação Superior. Resolução $n^{\circ}$ 8, de 11 de março de 2002c. Disponível em: http://portal.mec.gov.br/cne/arquivos/pdf/CES08-2002.pdf>. Acesso em: 25 mar. 2017.

CONTRERAS, J. A autonomia de professores. São Paulo: Cortez, 2012.

DINIZ, M. Inclusão de pessoas com deficiência e/ou necessidades específicas: avanços e desafios. Belo Horizonte: Autêntica Editora, 2012.

FREITAS, H. C. L. Formação de Professores no Brasil: 10 anos de embate entre projetos de formação. Educação \& Sociedade, v. 23, n. 80, p. 136-167, Campinas, 2002. Disponível em: < http://www.scielo.br/pdf/es/v23n80/12928.pdf >. Acesso em: abr. 2017.

GATTI, B. A. Formação de Professores no Brasil: Características e Problemas. Educação \& Sociedade, v.31, n.113, p. 1355-1379, Campinas, 2010. Disponível em: < http://www.scielo.br/pdf/es/v31n113/16.pdf >. Acesso em: abr. 2017.

GREENBERG, A. Uma Breve História da Química: Da Alquimia as Ciências 
GUEDES, N. C.; FERREIRA, M. S. História e Construção da Profissionalização nos Cursos de Licenciatura. Anais. II Congresso de História da Educação. Natal, 2002.

KASSEBOEHMER, A. C.; CORRÊA, R.G.; FERREIRA, L. H. A formação do licenciado em Química: um olhar sobre os cursos de formação inicial das instituições públicas do estado de São Paulo. Anais. XV Encontro Nacional de Ensino de Química. Brasília, 2010.

KRASILCHIK, M. Prática de Ensino de Biologia. São Paulo: Edusp, 2004.

LIBÂNEO, J. C. Organização e Gestão da Escola: Teoria e Prática. Goiânia: Ed. Alternativa, 2004.

LIBÂNEO, J. C.; OLIVEIRA, J. F.; TOSCHI, M. S. Educação escolar: políticas, estrutura e organização. São Paulo: Cortez, 2012.

LIMA, M. F.; ZANLORENZI, C. M. P; PINHEIRO, L. R. A função do currículo no contexto escolar. Curitiba: Ibpex, 2010.

LÔBO, S. F.; MORADILHO, E. F. Epistemologia e a formação docente em química. Química Nova na Escola, n.17, p. 39-41, 2003. Disponível em: <http://qnesc.sbq.org.br/online/qnesc17/a10.pdf >. Acesso em: mar. 2017.

LODI, A. C. B. Educação bilíngue para surdos e inclusão segundo a Política Nacional de Educação Especial e o Decreto n ${ }^{\circ}$ 5.626/05. Educação e Pesquisa, v.39, n.1, São Paulo, 2013. Disponível em: <https://dialnet.unirioja.es/descarga/articulo/4349761.pdf>. Acesso em: mar. 2017.

LOPES, A. R. C. Currículo e epistemologia. ljuí: Ed. Unijuí, 2007.

LUDKE, M.; ANDRÉ, M.E. E. D. A. A pesquisa em educação: abordagens qualitativas. São Paulo: EPU, 1986.

MESQUITA, N. A. S.; SOARES, M. H. F. B. Aspectos Históricos dos Cursos de Licenciatura em Química no Brasil nas Décadas de 1930 a 1980. Química Nova, v.34, n. 1, p.165-174, 2011. Disponível em:

<http://quimicanova.sbq.org.br/imagebank/pdf/Vol34No1_165_30-

AG09717.pdf>. Acesso em: mar. 2017.

MESQUITA, N. A. S.; CARDOSO, T. M. G.; SOARES, M. H. F. B. O Projeto de 
Disponível em: < http://www.scielo.br/pdf/qn/v36n1/v36n1a33.pdf >. Acesso em: mar. 2017.

PIMENTA, S. G.; LIMA, M. S. L. Estágio e Docência. Cortez Editora. São Paulo, 2004.

SANTOS, W.; SCHNETZLER, R. Educação em Química: compromisso com a cidadania. Editora ljuí: UNIJUÍ, 2000.

SCHNETZLER, R. P. A Pesquisa em Ensino de Química no Brasil: Conquistas e Perspectivas. Quim. Nova, v. 25, p. 14-24, 2002. Disponível em:

<http://www.scielo.br/pdf/qn/v25s1/9408.pdf >. Acesso em: abr. 2017.

SCHNETZLER, R. P. A Pesquisa no Ensino de Química e a Importância da Química Nova na Escola. Qnesc, n. 20, p. 49-54, 2004. Disponível em:

<http://qnesc.sbq.org.br/online/qnesc20/v20a09.pdf >. Acesso em: abr. 2017.

UNIVERSIDADE X. Projeto Pedagógico do Curso (PPC). 2010.

Resolução № 059/13 COGEP, 2013. Projeto de alteração da matriz curricular do curso de Licenciatura em Química para adequação do estágio supervisionado. Curitiba, 2013.

ZAINKO, M. A. S. Políticas de formação do professor e qualidade da educação básica: o projeto pedagógico das licenciaturas, os condicionantes da qualidade, 0 perfil dos professores e o desempenho dos estudantes no Estado do Paraná: análise dos projetos políticos pedagógicos de cursos de licenciaturas. Universidade Federal do Paraná, Pró-reitoria de Graduação e Educação Profissional, Curitiba: UFPR, 2015.

Recebido: 29 mai. 2017

Aprovado: 29 set. 2017

DOI: $10.3895 /$ actio.v2n2.6798

Como citar:

OLIVEIRA, T. A. L.; ALVES, F. I. M.; ALMEIDA, M. P.; DOMINGUES, F. A.; OLIVEIRA, A. L. Formação de Professores em Foco: Uma Análise Curricular de um Curso de Licenciatura em Química. ACTIO, Curitiba, v.

2, n. 2, p. 137-158, jan./jul.2017. Disponível em: <https://periodicos.utfpr.edu.br/actio>. Acesso em: XXX. Correspondência:

Thaís Andressa Lopes de Oliveira

Rua Miguel Garcia Gomes, Travessa Isaltino Batista Rodrigues, $n^{\circ} 74$. Conjunto São João, MandaguariParaná, Brasil.

Direito autoral: Este artigo está licenciado sob os termos da Licença Creative Commons-Atribuição 4.0 Internacional.

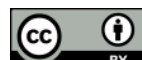

